\title{
RESEARCH
}

Open Access

\section{Pediatric emergency department visits during the COVID-19 pandemic: a large retrospective population-based study}

\author{
Claudio Barbiellini Amidei ${ }^{1}$, Alessandra Buja ${ }^{1 *}$ D, Andrea Bardin ${ }^{1}$, Filippo Bonaldi ${ }^{1}$, Matteo Paganini ${ }^{2}$
} Mariagiovanna Manfredi ${ }^{1}$, Andrea Favaro ${ }^{3}$, Vincenzo Baldo ${ }^{1}$, Mario Saia ${ }^{4}$ and Liviana Da Dalt ${ }^{1}$

\begin{abstract}
Background: COVID-19 pandemic has stretched healthcare system capacities worldwide and deterred people from seeking medical support at Emergency Departments (ED). Nevertheless, population-based studies examining the consequences on children are lacking.

Methods: All ED visits from 2019 to 2020 in Veneto, Italy (4.9 million residents) were collected. Anonymized records of pediatric ( $\leq 14$ years) ED visits included patient characteristics, arrival mode, triage code, clinical presentation, and discharge mode. Year-on-year variation of the main ED visit characteristics, and descriptive trends throughout the study period have been examined.

Results: Overall, 425,875 ED presentations were collected, 279,481 in 2019, and 146,394 in 2020 (- 48\%), with a peak $(-79 \%)$ in March-April (first pandemic wave), and a second peak (below -60\%) in November-December (second pandemic wave). Burn or trauma, and fever were the two most common clinical presentations. Visits for nonurgent conditions underwent the strongest reduction during both pandemic waves, while urgent conditions reduced less sharply. ED arrival by ambulance was more common in 2020 (4.5\%) than 2019 (3.5\%), with a higher proportion of red triage codes ( $0.5 \%$, and $0.4 \%$ respectively), and hospitalizations following ED discharge $(9.1 \%$, and $5.9 \%$ respectively).

Conclusion: Since the beginning of the COVID-19 pandemic, pediatric ED presentations underwent a steeper reduction than that observed for adults. Lockdown and fear of contagion in hospital-based services likely deterred parents from seeking medical support for their children. Given COVID-19 could become endemic, it is imperative that public health experts guarantee unhindered access to medical support for urgent, and less urgent health conditions, while minimizing infectious disease risks, to prevent children from suffering direct and indirect consequences of the pandemic.
\end{abstract}

Keywords: Pandemic, Children, Emergency department, Access to healthcare services, COVID-19

\footnotetext{
*Correspondence: alessandra.buja@unipd.it

'Department of Cardiologic, Vascular and Thoracic Sciences and Public Health, University of Padova, Via Loredan, 18, 35131 Padova, Italy

Full list of author information is available at the end of the article
}

C C The Author(s). 2021 Open Access This article is licensed under a Creative Commons Attribution 4.0 International License, which permits use, sharing, adaptation, distribution and reproduction in any medium or format, as long as you give appropriate credit to the original author(s) and the source, provide a link to the Creative Commons licence, and indicate if changes were made. The images or other third party material in this article are included in the article's Creative Commons licence, unless indicated otherwise in a credit line to the material. If material is not included in the article's Creative Commons licence and your intended use is not permitted by statutory regulation or exceeds the permitted use, you will need to obtain permission directly from the copyright holder. To view a copy of this licence, visit http://creativecommons.org/licenses/by/4.0/. The Creative Commons Public Domain Dedication waiver (http://creativecommons.org/publicdomain/zero/1.0/) applies to the data made available in this article, unless otherwise stated in a credit line to the data. 


\section{Introduction}

Since December 2019, 150 million people worldwide have been infected with SARS-CoV-2, and 3.15 million have died as of April 2021 [1]. Italy was hit particularly hard during the first, and second waves of the COVID19 pandemic (in spring and autumn 2020). By the end of December 2020, over 2.1 million cases and 77,583 deaths had been recorded in the country [2]. Children and adolescents accounted for only about $1-2 \%$ of confirmed COVID-19 cases [3], without age differences in the infection rates [4].

After the first clusters of COVID-19 cases were detected in Italy in late February 2020 [5], the government implemented social distancing rules and imposed strict restrictions on individual mobility for the whole country starting from March $10^{\text {th }}$. Sixty million people were placed under lockdown in the attempt to counter the disease's spread, and contain the burden, especially on hospital-based services and intensive care units [2]. The restrictions were gradually eased from May 2020 onwards, as the epidemic curve began to decline significantly. In October 2020, Italy was hit by a second wave of infections, prompting the government to reintroduce most of the restrictions adopted during the first wave. As the epidemic spread, intensive care units and hospitals dedicated to COVID-19 patients experienced a surge of admissions, while the use of other healthcare services decreased. In Italy, as in other hard-hit countries, the measures taken to cope with the pandemic led to a decline in the access rates to numerous healthcare services, including general practitioner and specialist visits, hospital admissions $[6,7]$, and emergency department (ED) visits $[6,8,9]$. Outpatient visits have recorded one of the strongest and most persistent drops since the start of the pandemic [10].

From a clinical perspective, children with SARS-CoV-2 infection are often asymptomatic or develop only a mild, shorter-lived illness compared to adults [11-14], but severe cases of pediatric COVID-19 have been described $[15,16]$.

A Spanish study reported a reduction in pediatric ED visits during the country's first pandemic wave, although the percentage of hospitalizations following ED visits had doubled [17]. This finding is suggestive of a tendency for parents to refrain from presenting their children at the ED during the pandemic, in absence of severe health conditions [18-21]. However, extensive evaluations of the impact of the COVID-19 pandemic on ED visits among children are currently lacking.

The aim of the present study was to conduct a detailed analysis of ED visits during 2019 and 2020, examining a large pediatric population in the Veneto region, northeastern Italy. We compared pre- and postpandemic trends in ED visits, focusing on different types of clinical presentations, and specific pediatric ED trajectories.

\section{Methods \\ Context}

In Italy, healthcare is made available to all citizens and residents through a mixed public-private system. The system is taxpayer-funded and administered on a regional basis, under regulations issued by the national Ministry of Health. The core principles of Italy's National Healthcare Service (NHS) are universality and equity of care. EDs provide non-stop free access for medical urgencies and emergencies. In absence of urgent conditions, patients are charged for the ED visit unless they are then hospitalized, or admitted to the brief-stay intensive care unit.

The present study was conducted in the Veneto region, northeastern Italy, which has a resident population of 4.9 million, with 52 active EDs at the time of the study (46 public and 6 private). Healthcare facilities in this area are organized into a regional network comprising: a) 7 major "hub" hospitals (including 2 university hospitals) with highly-specialized services, located in the major cities; b) 24 medium-sized "spoke" hospitals, each serving an average population of 250,000; and c) 21 small local hospitals. The smaller hospitals provide basic first-aid services, while the larger hospitals manage more complex conditions, pediatric surgical procedures, neonatal intensive care, and there are dedicated pediatric intensive care units [22, 23]. Veneto was initially one of the regions in Italy most severely affected by the COVID-19 epidemic, but its early public health response-which included a thorough case-finding and contact-tracing system, as well as a substantial increase in intensive care unit capacity, helped to prevent any breakdown of the regional healthcare system $[5,12]$.

\section{Materials}

Records of all children aged 14 or less arriving at any ED in Veneto during 2019 and 2020 were collected from a regional database where all ED visits are automatically recorded. The information available for each ED visit included: date of access, arrival mode, age, sex, clinical presentation, triage color code, and outcome. Three age brackets were chosen: less than 1 year, from 1 to 5 years, and from 6 to 14 years. Access mode was classified as walk-in, or by ambulance. Clinical presentations were grouped in one of the following 27 clinical categories: abdominal pain, acute neurological syndrome, allergic reactions, burn or trauma, chest pain, coma, dermatological symptoms, dyspnea, ear, nose and throat (ENT) disorders, fever, foreign object inhalation, forensic/legal medicine, gynecological disorders, hypertension, irritability, muscle pain, nephrological-urological disorders, 
nontraumatic hemorrhage, odontostomatological diseases, ophthalmological symptoms, other nervous system symptoms, other symptoms, poisoning, seizures, shock, social problems, tachycardia and palpitations. Triage color codes used to prioritize patients on arrival were: white tags for the mildest, not urgent conditions (lowest priority); green tags for mild conditions (low priority); yellow tags for urgent, potentially life-threatening conditions (high priority); and red tags for critical, life-threatening conditions (highest priority). Outcomes were classified as discharge at home, hospitalization, or death. Among all records, age was missing in 79 cases in 2019 and 3951 cases in 2020. These records were excluded from our analyses. Population data on confirmed cases of COVID-19, and patients hospitalized with symptoms probably attributable to the disease in Veneto region were retrieved from the database of the Italian Civil Protection Department, which monitors the coronavirus pandemic [13].

\section{Statistical analyses}

Monthly ED visits in 2020 were plotted against the number of new daily confirmed SARS-CoV-2 infections, as well as the number of hospitalized patients with symptoms suggestive of COVID-19 in Veneto, in the same period.

We calculated the variation in the number of ED visits in 2019 and 2020, grouped by: sex, age bracket, month of the year, triage color code, and clinical presentation. The bimestrial trend of ED visits for the 10 most common clinical presentations (over the entire study period) was then calculated for 2019 and 2020. The year-on-year percentage variation in the number of ED visits per month (comparing the same month in 2019 and in 2020) was measured, overall and stratified by triage code. The trajectories of ED visits grouped by arrival mode, triage code (excluding white color codes), and outcome were calculated for each of the two years considered, and analyzed descriptively. All analyses were carried out with $\mathrm{R}$ statistical software and Microsoft Excel.

\section{Ethical statement}

This study was conducted on data routinely collected by the healthcare services, using anonymized records. All analyses were performed on aggregated data. All data in Local Health Authority registries are recorded with the patient's consent and, once fully anonymized, can be used for research purposes without further authorization (Garante per la protezione dei dati personali, Resolution n. 85, March $\left.1^{\text {st }}, 2012\right)$. This study complies with the Declaration of Helsinki and the Italian Decree n. 196/ 2003 on personal data protection.

\section{Results}

In 2019 there were 279,481 ED visits in Veneto of children aged 14 years or less. In 2020 the visits almost halved, falling to 146,394. Figure 1 shows the number of monthly ED visits in 2020 plotted against the new daily cases of SARS-CoV-2 infections and hospitalized patients with COVID-19 symptoms, in Veneto region. A

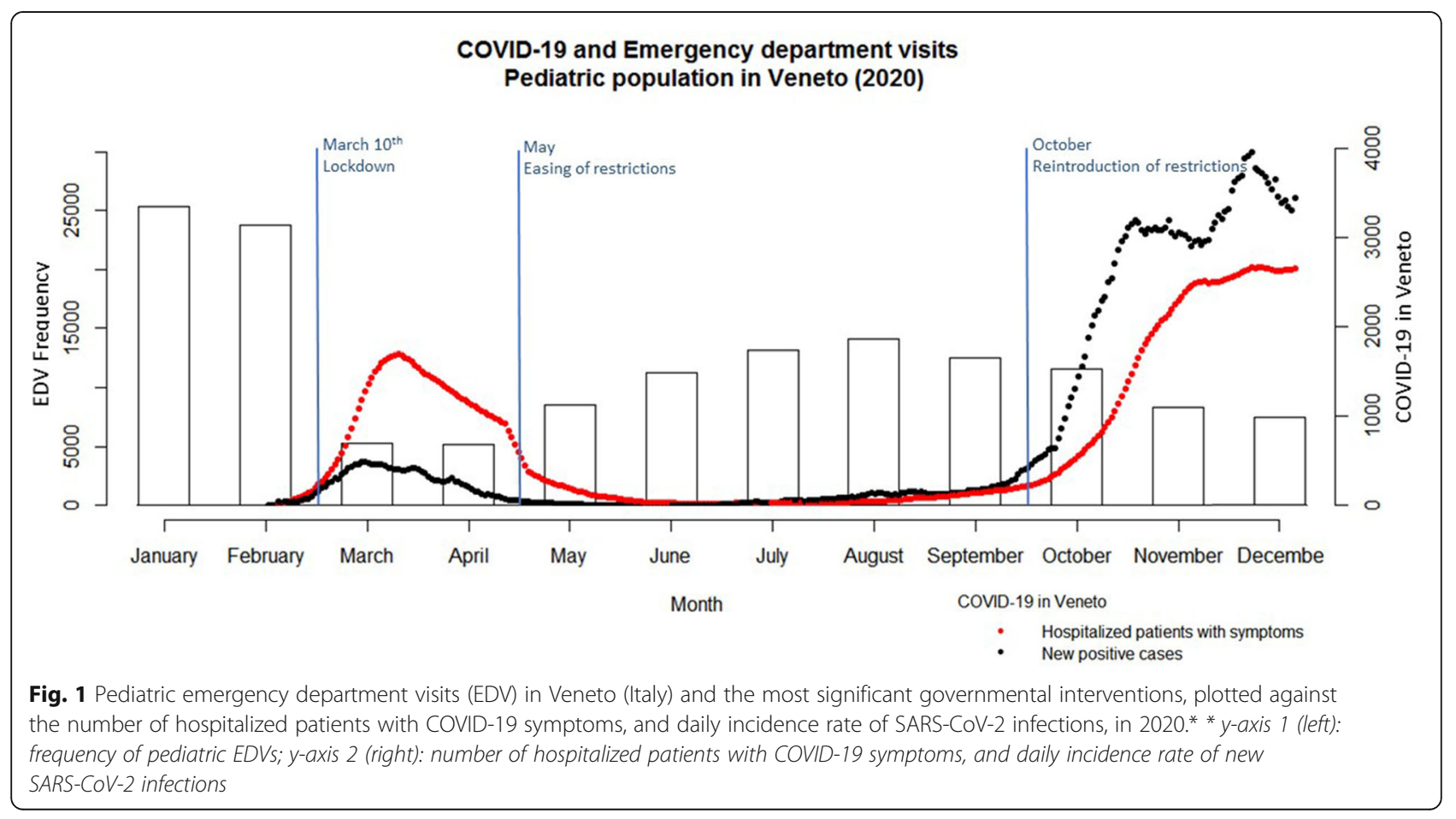


sudden drop in ED visits is already apparent in March and April 2020, at the time of the first wave of the COVID-19 pandemic in Europe. The number of COVID-19 cases started to decrease from May 2020, followed by a gradual increase in the frequency of pediatric ED visits during the summer. The number of visits then dropped again during autumn, although less sharply, as the second pandemic wave hit.

Table 1 shows the differences in the characteristics of pediatric ED visits in 2019 and 2020. The proportion of male and female patients did not vary substantially, nor did the age, despite a very sharp decrease $(-51.2 \%)$ among 1- to 5-year-olds in 2020. In the month-by-

Table 1 Pediatric emergency department visits in 2019 and 2020, grouped by sex, age, month, and triage color code

\begin{tabular}{|c|c|c|c|c|c|}
\hline & \multicolumn{2}{|l|}{2019} & \multicolumn{2}{|l|}{2020} & \multirow{2}{*}{$\begin{array}{l}\text { Variation } \\
2019-2020 \\
\% \\
\end{array}$} \\
\hline & $\mathrm{N}$ & $\%$ & $\mathbf{N}$ & $\%$ & \\
\hline Overall & 279,481 & & 146,394 & & $-47.6 \%$ \\
\hline \multicolumn{6}{|l|}{ Sex ${ }^{a}$} \\
\hline Male & 156,904 & $56.1 \%$ & 83,461 & $57.0 \%$ & $-46.8 \%$ \\
\hline Female & 122,576 & $43.9 \%$ & 62,933 & $43.0 \%$ & $-48.7 \%$ \\
\hline \multicolumn{6}{|l|}{ Age } \\
\hline 0 years & 34,548 & $12.4 \%$ & 18,716 & $12.8 \%$ & $-45.8 \%$ \\
\hline $1-5$ years & 118,746 & $42.5 \%$ & 57,942 & $39.6 \%$ & $-51.2 \%$ \\
\hline $6-14$ years & 126,187 & $45.2 \%$ & 69,736 & $47.6 \%$ & $-44.7 \%$ \\
\hline \multicolumn{6}{|l|}{ Month } \\
\hline January & 24,973 & $8.9 \%$ & 25,340 & $17.3 \%$ & $1.5 \%$ \\
\hline February & 25,449 & $9.1 \%$ & 23,747 & $16.2 \%$ & $-6.7 \%$ \\
\hline March & 24,764 & $8.9 \%$ & 5287 & $3.6 \%$ & $-78.7 \%$ \\
\hline April & 24,235 & $8.7 \%$ & 5180 & $3.5 \%$ & $-78.6 \%$ \\
\hline May & 23,052 & $8.3 \%$ & 8573 & $5.9 \%$ & $-62.8 \%$ \\
\hline June & 26,957 & $9.7 \%$ & 11,236 & $7.7 \%$ & $-58.3 \%$ \\
\hline July & 22,803 & $8.2 \%$ & 13,157 & $9.0 \%$ & $-42.3 \%$ \\
\hline August & 20,829 & $7.5 \%$ & 14,062 & $9.6 \%$ & $-32.5 \%$ \\
\hline September & 18,626 & $6.7 \%$ & 12,519 & $8.6 \%$ & $-32.8 \%$ \\
\hline October & 21,875 & $7.8 \%$ & 11,577 & $7.9 \%$ & $-47.1 \%$ \\
\hline November & 21,271 & $7.6 \%$ & 8273 & $5.7 \%$ & $-61.1 \%$ \\
\hline December & 24,647 & $8.8 \%$ & 7443 & $5.1 \%$ & $-69.8 \%$ \\
\hline \multicolumn{6}{|l|}{ Triage code } \\
\hline Red & 1239 & $0.4 \%$ & 749 & $0.5 \%$ & $-39.5 \%$ \\
\hline Yellow ${ }^{\mathbf{b}}$ & 23,031 & $8.2 \%$ & 15,013 & $10.3 \%$ & $-34.8 \%$ \\
\hline Green & 101,807 & $36.4 \%$ & 50,994 & $34.8 \%$ & $-49.9 \%$ \\
\hline White & 152,124 & $54.4 \%$ & 78,755 & $53.8 \%$ & $-48.2 \%$ \\
\hline Not indicated ${ }^{\mathbf{c}}$ & 1280 & $0.5 \%$ & 883 & $0.6 \%$ & $-31.0 \%$ \\
\hline
\end{tabular}

${ }^{a}$ Sex was missing in 1 record

b Orange triage color codes introduced in 2020 were merged with yellow codes for consistency across the study period

'Not indicated: includes patients arriving at the ED, but not being examined there (e.g., administrative registration) month comparison, the largest drop occurred in March and April 2020 (-78.7\% and $-78.6 \%$, respectively, compared with the same months in 2019). In both years, slightly more than half of all ED visits involved patients with non-urgent conditions (white triage color tags). There were slightly more cases tagged as yellow (urgent, potentially life-threatening conditions) in 2020 (10.3\%) than in 2019 (8.2\%), and the same was true for red triage codes (critical, life-threatening conditions), with $0.5 \%$ of all ED visits in 2020 as opposed to $0.4 \%$ in 2019.

Figure 2 shows the trends in the month-by-month variation grouped by triage color code, between 2019 and 2020. There was a steep drop in ED visits in spring 2020 for all triage codes, although visits that were assigned red, or yellow triage tags (clinical urgencies, and emergencies) decreased slightly less than green and white tags (non-urgent, or mild conditions). Comparing the two years, there is a reduction in all ED visits, for all triage codes in 2020, except for January $(+8.2 \%$ for white tags, in pre-pandemic times), and July $(+16 \%$ for red tags). When comparing 2019 with 2020 by triage code, the proportion of children with white, or green triage tags decreased more sharply $(-48.2 \%$ and $-49.9 \%$, respectively) than those with a yellow or red tag $(-34.8 \%$ and $-39.5 \%$, respectively).

Clinical presentation also varied significantly in 2019 and 2020. Burns and traumas were by far the most common clinical presentation in both years, accounting respectively for $27.9 \%$ and $32.1 \%$ of all pediatric ED visits although the number of visits for burns or traumas decreased by $39.8 \%$. As seen for ED visits overall, there was a substantial reduction from 2019 to 2020 in the number of ED visits for almost all clinical presentations considered. The most marked reductions concerned: irritability $(-71.0 \%)$, muscle pain $(-70.7 \%)$, forensic/legal medicine $(-64.2 \%)$, other nervous system symptoms $(-61.0 \%)$, and seizures (-60.7\%). ED visits for fever and dyspnea also decreased substantially in 2020 ($47.7 \%$ and $-48.3 \%$, respectively), but they continued to account for the same proportions of clinical presentations $(4.5 \%$ and $14.1 \%$, respectively $)$ in both years, as shown in Table 2 .

Figure 3 shows the bimestrial trends of the ten most common clinical presentations over the two years. Once again, the marked drop in the number of ED visits starting in March 2020 (and continuing throughout the year) concerned all these presentations. Burns or traumas remained the most common clinical presentation throughout the entire study period, followed by fever. Abdominal pain was the third most common presentation, except in the months of July and August 2020, when ear, nose and throat disorders became the third most frequent cause for pediatric ED visits. Overall, there were no major changes in the proportion of 


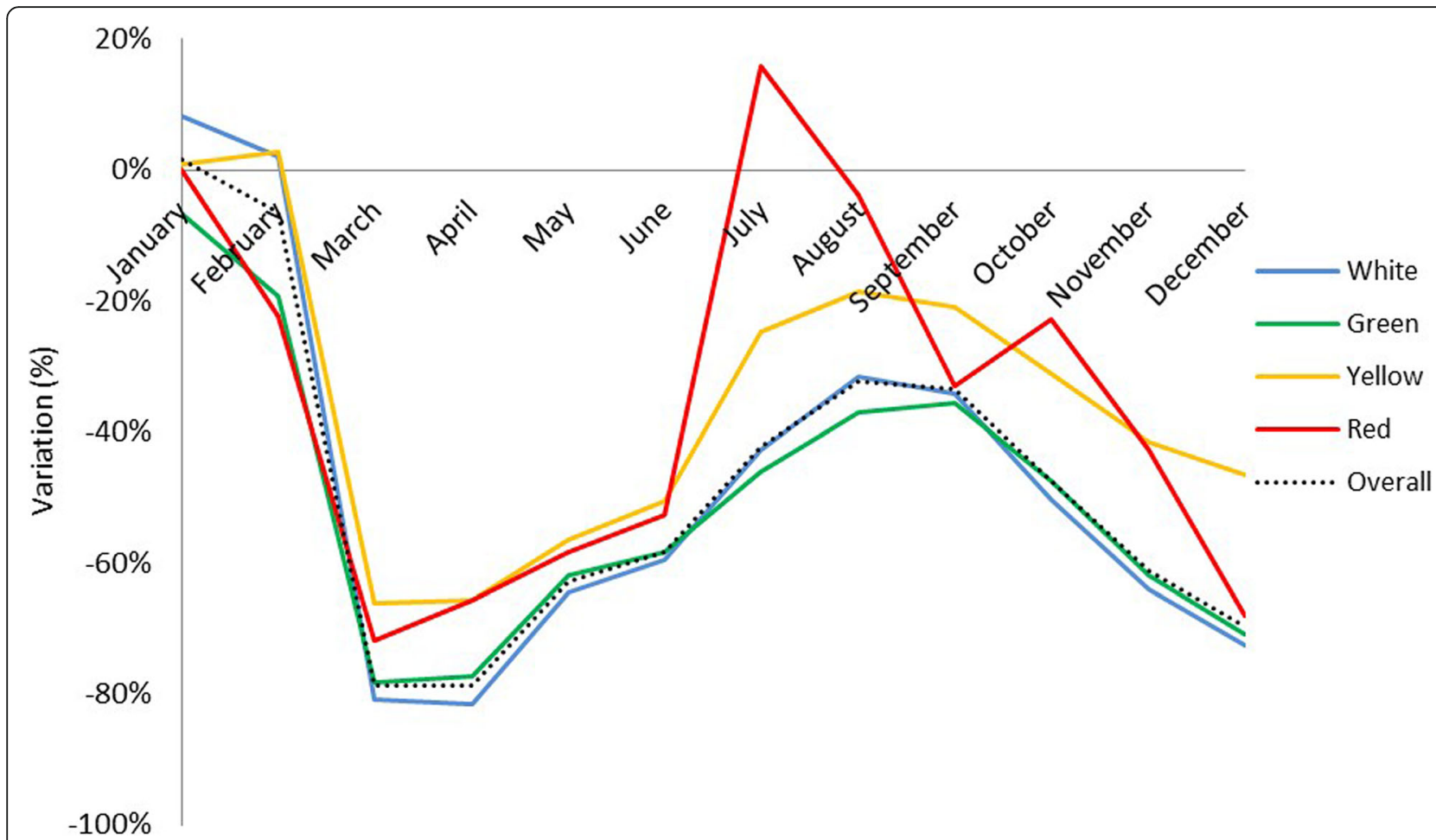

Fig. 2 Monthly year-on-year variation of triage color codes assigned to children in emergency departments in 2019 and 2020. Orange triage color codes introduced in 2020 were merged with yellow codes for consistency across the study period

each clinical presentation, as the sharp decline in ED visits affected them relatively homogenously. A subgroup analysis by age was also performed (Additional file 1), suggesting there are age-specific differences in the most frequent pediatric clinical presentations, although the overall impact of the pandemic, seems to have similarly affected ED visits across all age groups.

Figure 4 shows the trajectories of pediatric ED visits in 2019 and 2020 grouped by arrival mode, triage code (excluding white tags), and outcome. Arrival by ambulance rose in 2020 from 3.5 to $4.5 \%$, and the proportion of yellow, and red triage codes rose from 8.7 to $10.8 \%$ (data not shown). Outcomes such as death were extremely rare in both years (20 cases in 2019, and 15 in 2020), but the rate of hospital admissions following ED visits rose from $5.9 \%$ in 2019 to $9.1 \%$ in 2020 , and the proportion of patients with home discharge decreased from 94.1 to $90.9 \%$.

\section{Discussion}

To the best of our knowledge, few studies have examined in detail the effect of the COVID-19 pandemic on the trends of pediatric ED visits over two years. Many papers focused exclusively on ED admissions under lockdown, and very few studies were population-based [24-30].

The present study found a significant decrease in the number of pediatric ED visits in Veneto, in 2020 compared to the previous year. These findings suggest that the measures taken by the central government to contain the pandemic had a profound impact on the use of EDs, as well as on other healthcare services. They led to a sharp drop $(-48 \%)$ in all medical consultations compared with 2019, especially during the lockdown, when they decreased by $79 \%$ compared to the same months of the previous year, with a similar magnitude to that reported previously [30]. While the reduction in ED visits was more pronounced during the first and second waves of the pandemic, even with the loosening of restrictions during summer, they did not return to prepandemic levels. There could be various reasons for the sharp reduction during the pandemic, in addition to the authorities urging people to avoid using hospitalbased services unless it was strictly necessary. For instance, among children and adolescents, limited individual mobility lowered the risk of traumatic injuries, and social distancing reduced the chances of contracting other communicable diseases. It is an issue of concern, however, that parents might have avoided seeking hospital-based services for fear of contagion. This impression is supported by the greater proportion of urgencies and emergencies in 2020, indicating a general tendency of children to be presented at the ED for more severe conditions, as observed by a previous Italian study [30]. This is further confirmed by the $9.1 \%$ of pediatric 
Table 2 Variation in pediatric clinical presentations at emergency departments in 2019 and 2020, in Veneto region, Italy

\begin{tabular}{|c|c|c|c|c|c|}
\hline \multirow[t]{2}{*}{ Clinical presentation } & \multicolumn{2}{|l|}{2019} & \multicolumn{2}{|l|}{2020} & \multirow{2}{*}{$\begin{array}{l}\text { Variation 2019-2020 } \\
\%\end{array}$} \\
\hline & $\mathbf{N}$ & $\%$ & $\mathbf{N}$ & $\%$ & \\
\hline Abdominal pain & 25,764 & $9.2 \%$ & 10,414 & $7.1 \%$ & $-59.6 \%$ \\
\hline Acute neurological syndrome & 647 & $0.2 \%$ & 494 & $0.3 \%$ & $-23.6 \%$ \\
\hline Allergic reactions & 1953 & $0.7 \%$ & 865 & $0.6 \%$ & $-55.7 \%$ \\
\hline Burn or trauma & 77,799 & $27.9 \%$ & 46,826 & $32.1 \%$ & $-39.8 \%$ \\
\hline Chest pain & 1714 & $0.6 \%$ & 898 & $0.6 \%$ & $-47.6 \%$ \\
\hline Coma & 512 & $0.2 \%$ & 367 & $0.3 \%$ & $-28.3 \%$ \\
\hline Dermatological symptoms & 9501 & $3.4 \%$ & 3975 & $2.7 \%$ & $-58.2 \%$ \\
\hline Dyspnea & 12,559 & $4.5 \%$ & 6495 & $4.5 \%$ & $-48.3 \%$ \\
\hline ENT disorders ${ }^{a}$ & 12,073 & $4.3 \%$ & 5405 & $3.7 \%$ & $-55.2 \%$ \\
\hline Fever & 39,382 & $14.1 \%$ & 20,609 & $14.1 \%$ & $-47.7 \%$ \\
\hline Foreign object inhalation & 674 & $0.2 \%$ & 288 & $0.2 \%$ & $-57.3 \%$ \\
\hline Forensic/legal medicine & 215 & $0.1 \%$ & 77 & $0.1 \%$ & $-64.2 \%$ \\
\hline Gynecological disorders & 247 & $0.1 \%$ & 154 & $0.1 \%$ & $-37.7 \%$ \\
\hline Hypertension & 7 & $0.0 \%$ & 11 & $0.0 \%$ & $57.1 \%$ \\
\hline Irritability & 1655 & $0.6 \%$ & 480 & $0.3 \%$ & $-71.0 \%$ \\
\hline Muscle pain & 1429 & $0.5 \%$ & 419 & $0.3 \%$ & $-70.7 \%$ \\
\hline Nephrological-urological disorders & 2718 & $1.0 \%$ & 1691 & $1.2 \%$ & $-37.8 \%$ \\
\hline Nontraumatic hemorrhage & 774 & $0.3 \%$ & 488 & $0.3 \%$ & $-37.0 \%$ \\
\hline Odontostomatological diseases & 1061 & $0.4 \%$ & 547 & $0.4 \%$ & $-48.4 \%$ \\
\hline Ophthalmological symptoms & 4924 & $1.8 \%$ & 2456 & $1.7 \%$ & $-50.1 \%$ \\
\hline Other nervous system symptoms & 7855 & $2.8 \%$ & 3060 & $2.1 \%$ & $-61.0 \%$ \\
\hline Other symptoms & 73,461 & $26.3 \%$ & 38,679 & $26.5 \%$ & $-47.3 \%$ \\
\hline Poisoning & 616 & $0.2 \%$ & 477 & $0.3 \%$ & $-22.6 \%$ \\
\hline Seizures & 509 & $0.2 \%$ & 200 & $0.1 \%$ & $-60.7 \%$ \\
\hline Shock & 220 & $0.1 \%$ & 118 & $0.1 \%$ & $-46.4 \%$ \\
\hline Social problems & 108 & $0.0 \%$ & 83 & $0.1 \%$ & $-23.1 \%$ \\
\hline Tachycardia and palpitations & 753 & $0.3 \%$ & 388 & $0.3 \%$ & $-48.5 \%$ \\
\hline Overall $^{b}$ & 279,130 & $100.0 \%$ & 145,964 & $100.0 \%$ & $-47.7 \%$ \\
\hline
\end{tabular}

${ }^{a}$ ENT: Ear, nose and throat

${ }^{b}$ Records with missing clinical presentations have been excluded from the analyses $(N=781)$

patients arriving at the ED in 2020 being hospitalized, with a sharp increase compared to the $5.9 \%$ recorded in 2019. A similar phenomenon had already been observed in 2003, when the fear of contracting SARS from patients, and healthcare workers, had deterred people from seeking care [31]. Now that the epidemic curve has improved, large numbers of citizens, including adolescents, have been vaccinated against SARS-CoV-2, and restrictions are gradually being lifted, it will be very important to see whether ED visits will remain lower than those seen before the COVID-19 pandemic. It is imperative for public health services to ensure that urgent medical care needs continue to be met. Monitoring health parameters in children following such an unprecedented reduction in ED visits, might shed light on its possible consequences. It is particularly worth focusing on the nonurgent conditions that were reportedly responsible for overcrowding at the EDs in pre-COVID-19 times. Children under 14 years seem to be amongst the least vulnerable to COVID-19, with only 176 hospitalizations in Veneto up to April 2021 (and infants up to 12 months accounted for $56 \%$ of these hospitalizations). Future studies should therefore try to clarify whether the persistent reduction in pediatric ED visits has paved the way for a more appropriate use of this acute healthcare service, or whether children have been suffering, as an indirect consequence of COVID19 , from inadequate medical support [25, 32]. If no detrimental consequences were to be found, the pandemic could provide a unique opportunity to shift the 


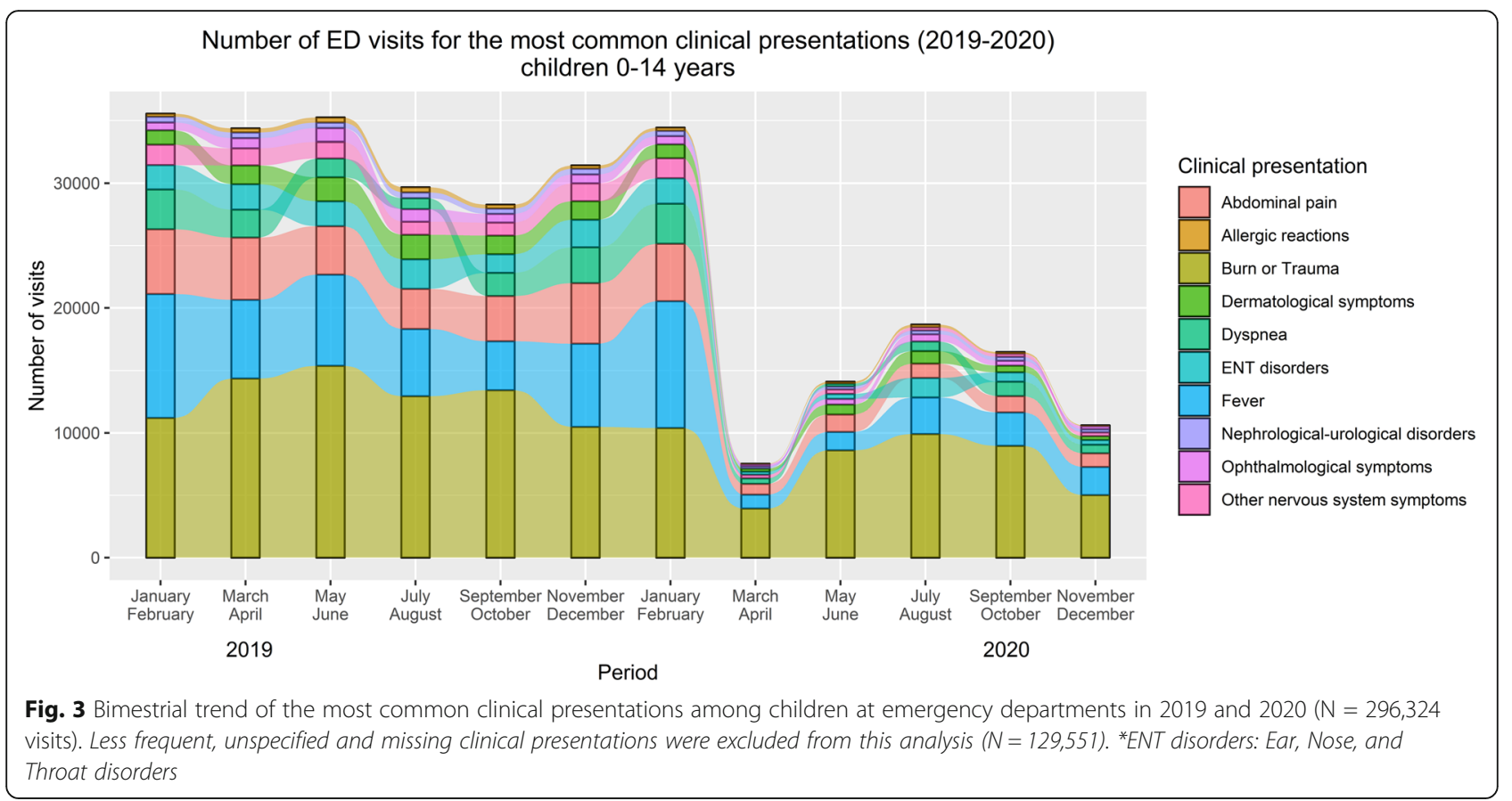

center of pediatric emergency healthcare support to an integrated network of primary care pediatricians. This would allow to relieve hospital emergency departments from overcrowding for nonurgent conditions, and ensure more efficient support for patients presenting with severe conditions.

Our findings are consistent with previous literature on COVID-19 in other Italian regions. Several studies, in fact, reported a decline in all ED visits during the first lockdown that ranged from 62 to $81 \%$, similarly to the rates found in the present study [25-27, 30]. The reduction seems to have affected the whole pediatric population to the same degree, without sex, or age differences [33].

In a cross-sectional study conducted on 27 pediatric EDs in the USA from mid-March to the end of August 2020, a decline in consultations could be seen even before the surge in SARS-CoV-2 cases. Interestingly, the study showed that the greatest decrease concerned visits for respiratory disorders. This could be explained by the

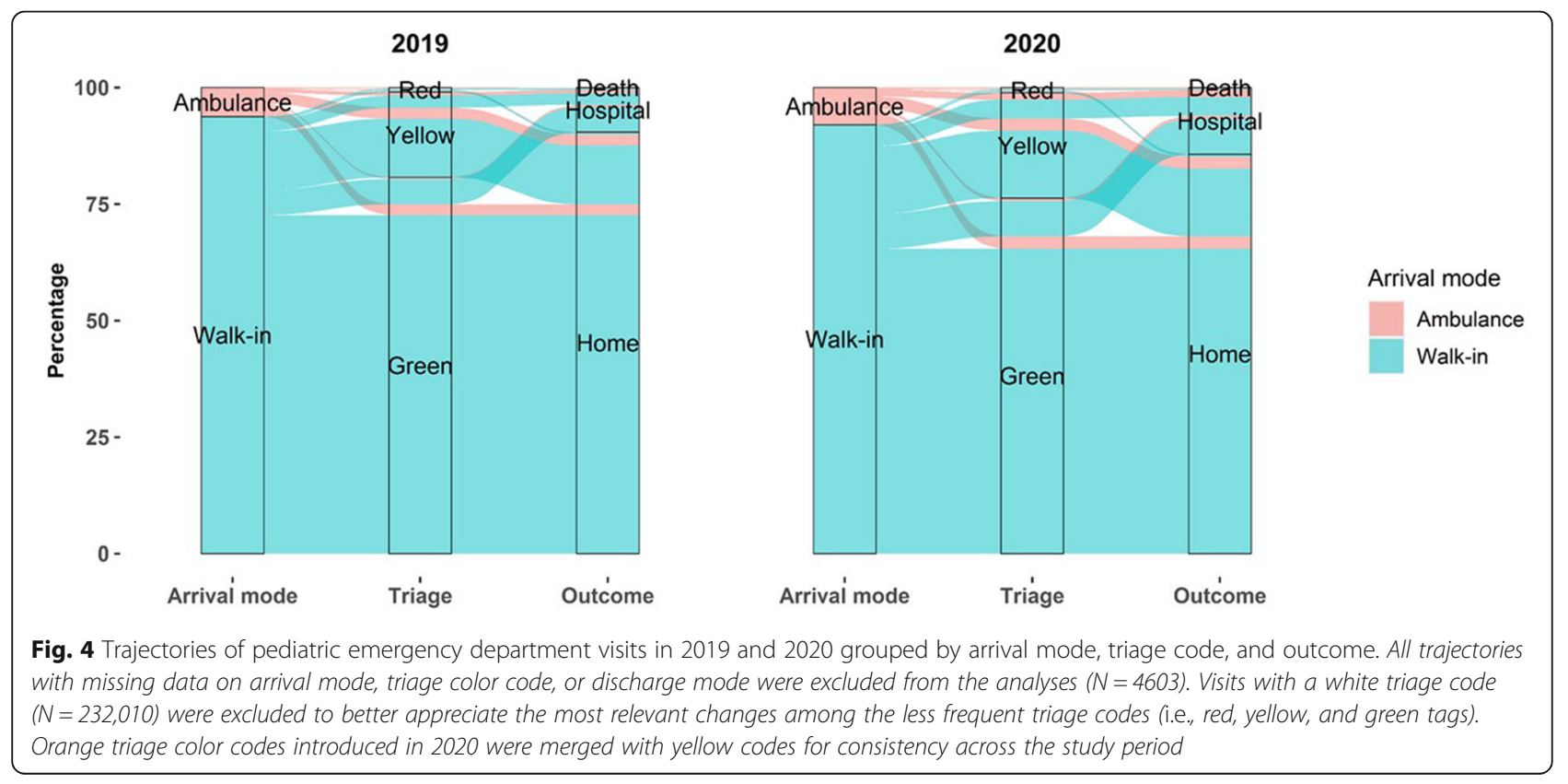


widespread use of personal protective equipment (especially N95 respirators, and surgical masks) that led to a marked reduction in the circulation of all sorts of viruses, most of which had lower effective reproduction numbers (Rt) than SARS-CoV-2. The very low rates of flu observed during the flu season of 2019 and 2020 [34] are also suggestive of a possible effect played by personal protective equipment, combined with social distancing. The air filtering effect of personal protective equipment would also have reduced exposure to air pollution and pollens, ultimately leading to lower rates of respiratory symptoms (e.g. dyspnea, bronchitis, upper airway symptoms) [24]. Restricting social contacts, promoting intensive use of personal protective equipment, and potentiating hygiene measures (such as frequent hand washing) could also help explain the reduction in ED visits for clinical presentations relating to infectious diseases. Burns or traumas showed a less marked decline in our data $(-40 \%)$ compared to previous studies, probably linked to an increase in the number of domestic accidents [24, 35]. Similar trends to those found in Veneto region, were reported in two retrospective reviews concerning two tertiary pediatric hospitals in Singapore, which compared the first 6 months of 2020, with the same period in 2019 [28, 29]. The common findings of studies conducted in diverse populations suggest these phenomena might have similar effects in different settings.

The present work has several strengths, in particular a large population with a broad set of detailed information regarding each ED visit. Given our country's national health service, the data discussed here are not at risk of bias, because almost all medical emergencies are managed by public hospitals, or publicly-funded private hospitals (that were included in our analyses). This enabled us to perform stratified analyses to shed light on specific phenomena that could have differentially affected particular subgroups during the COVID-19 pandemic. By representing trajectories (i.e. arrival mode, triage code, and outcome), we were able to compare ED paths before and after the pandemic. Limitations of this study include the lack of detailed information on comorbidities of children accessing the EDs, which prevented us from considering further clinical aspects, other than the type of clinical presentation on arrival at the ED. Certain clinical presentations underwent minor changes during the study period, but they were grouped to ensure full comparability. No data were available for children infected with SARS-CoV-2, so we could not examine the direct effects of the virus on pediatric ED presentations, in regards to arrival mode, triage urgency color tags, or outcome.

In conclusion, COVID-19 had a very strong impact in reducing the numbers of pediatric ED visits in Veneto region in 2020, and this was especially evident during the first lockdown in spring. The decline in ED consultations was especially marked for nonurgent medical conditions (white, and green triage tags), suggesting children with these conditions were less likely to be brought to an ED. The numbers of ED visits dropped steeply for all clinical presentations, but within each year, their ratio remained relatively stable, suggesting the absence of any differential effect of the pandemic on specific pediatric conditions.

The COVID-19 pandemic has prompted unprecedented changes in access to healthcare services that deserve to be examined in detail. Policy makers should monitor the long-term effects of the pandemic on children, and tailor policies to maximize the efficacy of healthcare services in countering the spread of infectious diseases, without negatively affecting the quality of acute healthcare support. In a world where SARS-CoV-2 variants could become endemic, or new viruses could develop pandemic characteristics, it is imperative to ensure that people in general, but children especially, be constantly guaranteed full medical support in case of medical urgencies or emergencies, in the safest possible environment.

\section{Supplementary Information}

The online version contains supplementary material available at https://doi. org/10.1186/s13052-021-01168-4.

Additional file 1. Trends in emergency department visits stratified by age group (0, 1-5, and 6-14 years).

\section{Acknowledgements}

Not applicable.

Authors' contributions

Buja conceived the study. Baldo \& Buja developed the methods. Barbiellini Amidei tested the analyses. Bardin, Barbiellini Amidei, Matteo Paganini, Mariagiovanna Manfredi, Andrea Favaro, wrote the draft. Mario Saia \& Liviana Da Dalt, supervised the project and approved the final draft. All authors read and approved the final manuscript.

\section{Funding}

The study did not receive any funding.

\section{Availability of data and materials}

The data supporting the findings of this study are held by the Veneto Epidemiological Registry and were used under license for the present work, but they are not publicly available. These data are nonetheless available from Alessandra Buja (alessandra.buja@unidp.it) on reasonable request, and subject to permission being obtained from the Veneto Epidemiological Registry (Veneto Regional Authority).

\section{Declarations}

Ethics approval and consent to participate Not applicable.

Consent for publication Not applicable. 


\section{Competing interests}

The authors declare that the research was conducted in the absence of any commercial or financial relationships that could be construed as a potential conflict of interest

\section{Author details \\ 'Department of Cardiologic, Vascular and Thoracic Sciences and Public Health, University of Padova, Via Loredan, 18, 35131 Padova, Italy. 2Department of Biomedical Sciences, University of Padova, Padova, Italy. ${ }^{3}$ Emergency Department and Emergency Medical Service, "San Bassiano" Hospital, ULSS 7 "Pedemontana", Bassano del Grappa, Italy. ${ }^{4}$ Clinical Governance Unit, Azienda Zero, Padova, Italy.}

Received: 2 August 2021 Accepted: 4 October 2021

Published online: 04 November 2021

\section{References}

1. Statement on the second meeting of the International Health Regulations (2005) Emergency Committee regarding the outbreak of novel coronavirus (2019-nCoV). Accessed June 19, 2021. https://www.who.int/news/item/3001-2020-statement-on-the-second-meeting-of-the-international-healthregulations-(2005)-emergency-committee-regarding-the-outbreak-of-novelcoronavirus-(2019-ncov).

2. Trova Norme \& Concorsi - Normativa Sanitaria. Accessed June 19, 2021 https://www.trovanorme.salute.gov.it/norme/dettaglioAtto?id=73629

3. Rajapakse N, Dixit D. Human and novel coronavirus infections in children: a review. Paediatr Int Child Health. 2021;41(1):36-55. https://doi.org/10.1080/2 0469047.2020.1781356.

4. Transmission of COVID-19. https://www.ecdc.europa.eu/en/covid-19/latestevidence/transmission

5. Guzzetta G, Riccardo F, Marziano V, et al. Impact of a Nationwide Lockdown on SARS-CoV-2 Transmissibility, Italy. Emerg Infect Dis. 2021;27(1):267-70. https://doi.org/10.3201/eid2701.202114.

6. Birkmeyer JD, Barnato A, Birkmeyer N, Bessler R, Skinner J. The impact of the COVID-19 pandemic on hospital admissions in the United States: study examines trends in US hospital admissions during the COVID-19 pandemic. Health Aff (Millwood). 2020;39(11):2010-7. https://doi.org/10.1377/hlthaff.202 0.00980 .

7. Nuñez JH, Sallent A, Lakhani K, Guerra-Farfan E, Vidal N, Ekhtiari S, et al. Impact of the COVID-19 pandemic on an emergency traumatology service: experience at a tertiary trauma Centre in Spain. Injury. 2020;51(7):1414-8. https://doi.org/10.1016/j.injury.2020.05.016.

8. Mishra SK, Tripathi T. One year update on the COVID-19 pandemic: Where are we now? Acta Trop. 2021;214:105778. https://doi.org/10.1016/j.acta tropica.2020.105778.

9. Vilar S, Isom DG. One year of SARS-CoV-2: how much has the virus changed. Biology. 2021;10(2):91. https://doi.org/10.3390/biology10020091.

10. Mehrotra A, Chernew M, Linetsky D, Hatch H, Cutler D. The Impact of the COVID-19 Pandemic on Outpatient Visits: Practices Are Adapting to the New Normal. In: . https://www.commonwealthfund.org/publications/2020/ jun/impact-covid-19-pandemic-outpatient-visits-practices-adapting-newnormal.

11. Munro APS, Faust SN. COVID-19 in children: current evidence and key questions. Curr Opin Infect Dis. 2020;33(6):540-7. https://doi.org/10.1097/ QCO.0000000000000690.

12. Liguoro I, Pilotto C, Bonanni M, Ferrari ME, Pusiol A, Nocerino A, et al. SARSCOV-2 infection in children and newborns: a systematic review. Eur J Pediatr. 2020;179(7):1029-46. https://doi.org/10.1007/s00431-020-03684-7.

13. Di Nardo M, van Leeuwen $G$, Loreti A, et al. A literature review of 2019 novel coronavirus (SARS-CoV2) infection in neonates and children. Pediatr Res. 2021;89(5):1101-8. https://doi.org/10.1038/s41390-020-1065-5.

14. Dong Y, Mo X, Hu Y, Qi X, Jiang F, Jiang Z, et al. Epidemiology of COVID-19 among children in China. Pediatrics. 2020;145(6):e20200702. https://doi.org/1 0.1542/peds.2020-0702.

15. Moreno-Galarraga L, Urretavizcaya-Martínez M, Alegría Echauri J, García Howard M, Ruperez García E, Aguilera-Albesa S, et al. SARS-CoV-2 infection in children requiring hospitalization: the experience of Navarra. Spain World J Pediatr. 2020;16(6):614-22. https://doi.org/10.1007/s12519-020-00393-X.

16. Castagnoli R, Votto M, Licari A, Brambilla I, Bruno R, Perlini S, et al. Severe acute respiratory syndrome coronavirus 2 (SARS-CoV-2) infection in children and adolescents: a systematic review. JAMA Pediatr. 2020;174(9):882-9. https://doi.org/10.1001/jamapediatrics.2020.1467.

17. Ramos-Lacuey B, Aguirre MH, Gallego CC, AlL d M, Esarte EG, MorenoGalarraga L. ECIEN-2020 study: the effect of COVID-19 on admissions for non-COVID-19 diseases. World J Pediatr. 2021;17(1):85-91. https://doi.org/1 0.1007/s12519-020-00406-9.

18. Tuominen J, Hällberg V, Oksala N, Palomäki A, Lukkarinen T, Roine A. NYUEDA in modelling the effect of COVID-19 on patient volumes in a Finnish emergency department. BMC Emerg Med. 2020;20(1):97. https://doi.org/1 0.1186/s12873-020-00392-1.

19. Bellan M, Sainaghi PP, Gavelli F, Patrucco F, Avanzi GC, Pirisi M, et al Lessons from the Italian COVID-19 frontline. Minerva Med. 2020;111(4):303-5 Accessed June 19, 2021. https://www.minervamedica.it/en/journals/minervamedica/article.php?cod=R10Y2020N04A0303.

20. Pata D, Gatto A, Buonsenso D, Chiaretti A. A COVID-19 outbreak's lesson: Best use of the paediatric emergency department. Acta Paediatr Oslo Nor 1992. 2020;109(9):1903-4. https://doi.org/10.1111/apa.15386.

21. Manzoni P, Militello MA, Fiorica L, Cappiello AR, Manzionna M. Impact of COVID-19 epidemics in paediatric morbidity and utilisation of Hospital Paediatric Services in Italy. Acta Paediatr Oslo Nor 1992. 2021;110(4):136970. https://doi.org/10.1111/apa.15435.

22. Toniolo F, Mantoan D, Maresso A. Health Systems in Transition Veneto Region Italy. Health Syst Rev. https://www.euro.who.int/_data/assets/pdf_ file/0007/162583/e96452.pdf.

23. Annuario Statistico Del Servizio Sanitario Nazionale.

24. DeLaroche AM, Rodean J, Aronson PL, et al. Pediatric emergency department visits at US Children's hospitals during the COVID-19 pandemic. Pediatrics. 2021;147(4):e2020039628. https:/doi.org/10.1542/peds.2020-039628.

25. Ciacchini B, Tonioli F, Marciano C, Faticato MG, Borali E, Pini Prato A, et al. Reluctance to seek pediatric care during the COVID-19 pandemic and the risks of delayed diagnosis. Ital J Pediatr. 2020;46(1):87. https://doi.org/10.11 86/s13052-020-00849-w.

26. Matera L, Nenna R, Rizzo V, Ardenti Morini F, Banderali G, Calvani M, et al. SARS-CoV-2 pandemic impact on pediatric emergency rooms: a multicenter study. Int J Environ Res Public Health. 2020;17(23):8753. https://doi.org/10.33 90/ijerph17238753.

27. Scaramuzza A, Tagliaferri $F$, Bonetti $L$, et al. Changing admission patterns in paediatric emergency departments during the COVID-19 pandemic. Arch Dis Child. 2020;105(7):704-6. https://doi.org/10.1136/a rchdischild-2020-319397.

28. Chong S-L, Soo JSL, Allen JC, et al. Impact of COVID-19 on pediatric emergencies and hospitalizations in Singapore. BMC Pediatr. 2020;20(1):562. https://doi.org/10.1186/s12887-020-02469-z

29. Tan RM, Ganapathy S, Tyebally A, et al. Paediatric emergency department attendances during COVID-19 and SARSin Singapore. Ann Acad Med Singap. 2021;50(2):126-34. https://doi.org/10.47102/annals-acadmedsg.2020500.

30. Raffaldi I, Castagno E, Fumi I, Bondone C, Ricceri F, Besenzon L, et al. Pediatric admissions to emergency departments of North-Western Italy during COVID-19 pandemic: a retrospective observational study. Lancet Reg Health Eur. 2021:5:100081. https://doi.org/10.1016/j.lanepe.2021.100081.

31. Chang H-J, Huang N, Lee C-H, Hsu Y-J, Hsieh C-J, Chou Y-J. The impact of the SARS epidemic on the utilization of medical services: SARS and the fear of SARS. Am J Public Health. 2004;94(4):562-4. https://doi.org/10.2105/AJPH. 94.4.562.

32. Vierucci F, Bacci C, Mucaria C, Dini F, Federico G, Maielli M, et al. How COVID-19 pandemic changed children and adolescents use of the emergency department: the experience of a secondary care pediatric unit in Central Italy. SN Compr Clin Med. 2020;2(11):1959-69. https://doi.org/10.1 007/s42399-020-00532-5.

33. Raucci U, Musolino AM, Di Lallo D, et al. Impact of the COVID-19 pandemic on the emergency department of a tertiary children's hospital. Ital J Pediatr. 2021;47(1):21. https://doi.org/10.1186/s13052-021-00976-y.

34. FluNews - Italia Rapporto della sorveglianza integrata dell'influenza. https:// www.epicentro.iss.it/influenza/flunews\#epi

35. Bressan S, Gallo E, Tirelli F, Gregori D, Dalt LD. Lockdown: more domestic accidents than COVID-19 in children. Arch Dis Child. 2021;106(2):e3. https:// doi.org/10.1136/archdischild-2020-319547.

\section{Publisher's Note}

Springer Nature remains neutral with regard to jurisdictional claims in published maps and institutional affiliations. 